\title{
Экология и сырье: сосуществование в сибирских технологиях эффективно!
}

Н.М. ЖУРАВЕЛЬ, кандидат экономических наук,

Институт экономики и организации промышленного производства СО РАН, Новосибирский национальный исследовательский государственный университет, Новосибирск.

E-mail: zhnela@mail.ru

В статье эколого-экономическая эффективность сибирских технологий оценивается на примере достижений ученых СО РАН в комплексной переработке литиевого сырья. Доказывается необходимость назревших изменений в расчетах эффективности при инвестиционном проектировании для учета экологоэкономического ущерба, предотвращаемого благодаря наилучшим доступным технологиям (технологии сорбционного обогащения и др.). Обосновано существенное положительное влияние экологических эффектов на экономическую эффективность принципиально новых сибирских технологий при комплексной переработке поликомпонентных литиеносных рассолов Сибирской платформы. Оцениваются причины, тормозящие внедрение этих технологий. Предлагаются административно-правовые меры для ускорения реализации наилучших доступных технологий в промышленном производстве.

Ключевые слова: комплексность, сибирская наука, наилучшая доступная технология, эколого-экономическая эффективность, ущерб

«Годом экологии» в РФ объявлен 2017-й. Статья преследует две цели. Во-первых, дать в определенной мере представление о спектре технологического богатства, создаваемого сибирской наукой, которое позволяет говорить о возможностях создания экологически чистого промышленного производства на основе комплексной переработки сырья. Во-вторых, обосновать существенное положительное влияние экологических эффектов принципиально новых сибирских технологий на их экономическую эффективность.

Характеристика «комплексного использования ископаемого (минерального) сырья» дана академиком А.Е. Ферсманом еще

\footnotetext{
* Статья подготовлена по плану НИР ИЭОПП СО РАН в рамках приоритетного
} направления XI.172 (проект XI.172.1.1.5). № 0325-2014-0009 в ИСГЗ ФАНО.

Автор выражает глубокую благодарность гл. науч. сотр. ИХТТМ СО РАН д.т.н. Н.П. Коцупало и гл. науч. сотр. ИЭОПП СО РАН к.э.н. М. А. Ягольницеру за консультативную помощь при подготовке статьи. 
в 1932 г. [1. С. 15]. Из трактовок современных авторов, в которых идеи и понятия А.Е. Ферсмана не претерпели принципиальных изменений, но получили более широкое толкование, приведем следующее: «Комплексное освоение недр может быть представлено как максимально полное выявление потенциально полезных для общества их свойств, рассматриваемых как совокупность ресурсов, постоянно наращиваемое на основе научно-технического прогресса хозяйственное их освоение, при одновременном или последовательном комплексном использовании всех ценных составляющих каждого ресурса для удовлетворения различных общественных потребностей на экономически приемлемой основе» [2. С. 66]. Эти авторы, проанализировав зарубежный и отечественный производственный опыт, приходят к однозначному выводу о существенных эколого-экономических преимуществах комплексного использования невозобновляемых минеральных ресурсов, о возможности существенного экономического роста и экологизации минерально-сырьевого комплекса при ограничении и даже снижении объемов добычи минерального сырья из недр.

Обратимся к достижениям сибирской науки при решении проблемы комплексной переработки сырья на примере важнейшего для экономики региона энергетического направления. Исходный ресурс в этом примере - гидроминеральное литиевое сырье, сопутствующее как газовым, так и нефтяным месторождениям.

Окончание XX века характеризуется стремительным увеличением сырьевой базы для производства литиевых продуктов за счет гидроминерального сырья - литиеносных природных рассолов, саларов, рапы озер. На долю гидроминерального сырья приходится $78 \%$ мирового содержания лития и только $22 \%$ - на традиционное рудное сырье. В отличие от руды гидроминеральное сырье не требует горных работ на добычу, а выщелачивание ценных компонентов из вмещающих пород осуществила сама природа. Содержание в рассолах таких компонентов, как соли лития, натрия, калия, магния, кальция, а также брома и ряда микрокомпонентов, позволяет их извлекать осадительными и ионообменными методами, на которые не нужны большие энергозатраты.

Литиеносные глубинные рассолы Сибирской платформы отличаются поликомпонентным составом с преимущественным содержанием кальция и магния и обогащены бромом. Институтом химии твердого тела и механохимии (ИХТТМ) СО РАН разработаны научные основы методики селективного извлечения лития из рассолов сложного состава. Результаты исследований позволили продолжить прикладные работы организованному для этих целей $3 \mathrm{AO}$ «Экостар-Наутех» и разработать технологию сорбционого обогащения по литию применительно к литиеносным рассолам любого состава [3].

Из месторождений Сибирской платформы наиболее обогащены по литию глубинные рассолы Иркутской области, наименее - попутные нефтяные рассолы (Юрубченское месторождение), но даже в них содержание лития превышает значения промышленных кондиций примерно в пять раз. Сорбционное обогащение по литию этих рассолов по методике «Экостара» позволило получить литиевый концентрат, сохранив солевой фон рассола практически неизменным. Поскольку солевой фон рассола на 50-70\% представляют хлориды кальция и магния, при комплексной переработке таких рассолов целесообразно получать не только литиевые, бромные и магниевые продукты, но и востребованные на рынке соли кальция. Как утверждают авторы [3], без получения этих товарных продуктов после извлечения лития потребуется закачка практически полного объема добытого рассола в пласты-коллекторы, что требует определенных капитальных и энергетических затрат. Между тем продукты на основе кальция и магния, полученные осаждением из рассола, пользуются большим спросом на мировом рынке как более качественные.

На основании проведенных исследований и опытно-промышленных испытаний авторами сорбционного обогащения показана возможность полной переработки добытых глубинных подземных рассолов, пересыщенных по содержанию хлорида кальция, что позволяет создать замкнутую безотходную технологию с широким ассортиментом получаемой товарной продукции. При этом авторы полагают, что, используя $\mathrm{CO}_{2}$, содержащийся в топочном газе объектов энергетики, и электролиз маточного раствора хлорида натрия непосредственно на месторождении рассолов, представляется реальным производить реагенты, необходимые для основных технологических процессов при организации 
химико-металлургического производства с получением лития, магния и кальция и сплавов на их основе.

Возможность экономичной добычи рассолов хлоридного кальциево-магниевого типа и инновационные технологические решения по их переработке были всесторонне апробированы на сырье Знаменского месторождения; подтвердились технологические, экономические и экологические преимущества этой технологии для промышленного применения.

Подтверждена расчетами также экономическая целесообразность организации производства комплексной переработки рассолов, сопутствующих Ковыктинскому газоконденсатному месторождению (Иркутская обл.). Эта технология обеспечивает возможность последовательно-параллельного получения товарных продуктов и не исключает индивидуального извлечения компонентов по мере готовности того или иного технологического передела и его аппаратурного оформления [4].

Выбор месторождения обусловлен наличием инфраструктуры и информацией о перспективности запасов рассола, необходимого для организации крупного химического комплекса. Проведены расчеты для четырех вариантов различной организации производственного комплекса с разным ассортиментом выпускаемой продукции.

Расчетный срок функционирования производства определяется запасами рассола и составляет 20 лет, включая строительство и ввод предприятия на полную проектную мощность.

Доказано, что повышение комплексности переработки полезных компонентов рассола значительно улучшает показатели эффективности: при увеличении номенклатуры выпускаемой продукции из сырья данного вида чистая прибыль возрастает в 3,3 раза, тогда как капитальные затраты и операционные издержки - только в 1,4 раза (таблица).

Особенно высокие показатели можно получать при организации на базе данного сырьевого источника химико-металлургического производства. Спрос на его продукцию обеспечивается бурным развитием авиакосмической промышленности, которое требует расширения производства металлов и легких сплавов на основе лития и магния.

Приведенные расчеты выполнены на основании результатов опытно-промышленных и укрупненных испытаний предлагаемых технологий. При этом все технологии получения товарных продуктов, положенные в основу технико-экономических расчетов, защищены патентами РФ [3].

Интегральные показатели экономической эффективности переработки литиеносного поликомпонентного гидроминерального сырья Ковыктинского месторождения за 20-летний период функционирования проекта

\begin{tabular}{|c|c|c|c|c|}
\hline \multirow{2}{*}{ Показатель } & \multicolumn{4}{|c|}{ Вариант переработки } \\
\hline & 1 -й & 2-й & 3-й & 4-й \\
\hline \multicolumn{5}{|l|}{ Объем выпуска продукции, тыс. т : } \\
\hline $\begin{array}{l}\text { противогололедный материал на основе хлоридов } \\
\text { кальция и магния (ПХКМ) }\end{array}$ & 3800 & 3800 & 3800 & 3800 \\
\hline карбонат лития технический & 31,5 & 31,5 & & 31,5 \\
\hline литийсодержащие фтористые соли & 96,8 & 96,8 & - & 96,8 \\
\hline бром & - & 203 & - & 203 \\
\hline бромид лития & - & 67,7 & - & 67,7 \\
\hline оксид магния & - & - & 1155 & 1089 \\
\hline буровые растворы, тыс. м $^{3}$ & - & - & 24915 & 24915 \\
\hline рассол, тыс. м & 16500 & - & - & -1 \\
\hline Стоимость реализованной продукции, млн руб. & 31387 & 44236 & 45726 & 74809 \\
\hline $\begin{array}{l}\text { Капитальные затраты, всего, млн руб. } \\
\text { Из них: }\end{array}$ & 1365 & 1610 & 1395 & 1900 \\
\hline производство рассола & 280 & 280 & 280 & 280 \\
\hline производство ПХКМ & 210 & 210 & 210 & 210 \\
\hline литиевое производство & 260 & 260 & - & 260 \\
\hline бромное производство & - & 245 & - & 245 \\
\hline магниевое производство & - & - & 290 & 290 \\
\hline здания и сооружения & 365 & 365 & 365 & 365 \\
\hline $\begin{array}{l}\text { производственная инфраструктура (сети, газопро- } \\
\text { вод, автолороги) }\end{array}$ & 250 & 250 & 250 & 250 \\
\hline $\begin{array}{l}\text { Операционные издержки (с учетом налогов и плате- } \\
\text { жей), млн руб. }\end{array}$ & 15531 & 17761 & 19124 & 22668 \\
\hline Чистая прибыль, млн руб. & 12051 & 20121 & 20160 & 39627 \\
\hline Чистый дисконтированный доход, млн руб. & 1909 & 3822 & 3498 & 8018 \\
\hline Внутренняя норма доходности,\% & 34,4 & 48,5 & 41,9 & 64,9 \\
\hline Срок окупаемости проекта (дисконтированный), лет & 5,9 & 4,5 & 5,4 & 4,2 \\
\hline
\end{tabular}

Вопросы комплексной переработки самого газоконденсатного сырья Ковыктинского и Чаяндинского месторождений Восточной Сибири при реализации проекта «Сила Сибири» детально рассматриваются в [5]. Автор дает содержательную 
оценку социально-экономических эффектов, которые порождает этот проект: «Основной эффект от разработки Ковыктинского и Чаяндинского месторождений Россия получит не столько за счет экспорта газа, сколько за счет предприятий по глубокой переработке газа, и в первую очередь предприятий газохимии... Из газа будут выделяться этан, бутан, пентан-гексановая фракция и гелий...» [5. С. 158]. Именно гелию автор предрекает «главный прорыв» в обосновании экономической эффективности освоения базисных месторождений «Силы Сибири».

Экономические преимущества комплексной переработки глубинных рассолов Сибирской платформы по сравнению с отдельными производствами всего набора получаемых продуктов в целом очевидны. В частности, это касается отсутствия дополнительных затрат на сырье, резкого сокращения затрат на все виды энергии, экономии на капитальных затратах и значительной части эксплуатационных затрат. Что же касается сокращения ущерба окружающей среде, то приближенно оценить его можно по изложенным выше данным, воспользовавшись обобщенными отраслевыми коэффициентами ущерба, рассчитанными автором [6] на основе методики [7] и статистической информации по РФ.

Взяв за основу расчета размаха величины ущерба коэффициенты ущерба по газовой и химической промышленности, равные 0,152 и 0,113 руб./руб. продукции, и данные из таблицы о стоимости реализованной продукции, получаем оценочную информацию о возможном размере ущерба по рассмотренным четырем вариантам организации производственного комплекса (млрд руб.): 3,5-4,8; 5,0-6,7; 5,2-6,9; 8,5-11,4. Очевидно, что величина стоимостного ущерба превосходит объемы приведенных в таблице капитальных затрат. Если же оценить накопленный эффект от сокращения ущерба за 20-летний период, мы увидим, что, во-первых, достигается существенный экологический эффект большей сохранности окружающей среды (ущерб природным комплексам, конечно, будет наноситься, но в меньшем размере); во-вторых, напрашивается вывод об ускоренной окупаемости инвестиций в полный цикл производства за счет предотвращения ущерба. Правда, на практике это станет возможным лишь при экологизации основ проектного финансирования [8], сегодня категория предотвращенного экологического ущерба, увы, не входит в схему расчета финансовых показателей эффективности инвестиционных проектов.

А теперь попробуем разобраться, почему представленная выше технология с отличными эколого-экономическими показателями практически бездействует в России. В то же время она уже несколько лет успешно работает в Китае, на ее внедрение в настоящее время оформляются договоры с заказчиками из Боливии.

Итак, есть разработчики ноу-хау с патентами на все методы и технологическое оформление комплексной переработки сырья из рассолов, сопутствующих газовым и нефтяным месторождениям. Есть собственники месторождений в лице государственных и частных компаний. Есть органы управления собственностью на трех уровнях: муниципальном, региональном, народнохозяйственном. И есть Министерство экономического развития РФ, ответственное за то, чтобы развитие экономики осуществлялось путем замены устаревающего технологического базиса на более эффективный с позиций экономики и экологии технологический уклад пятого и шестого поколений.

Очевидно, что из четырех участников процесса освоения наилучшей доступной технологии ее разработчики по определению не являются тормозом на пути освоения (не враги же они своему детищу). Судя по тому, что технология пользуется спросом за рубежом, собственники сырья тоже должны быть заинтересованы в его комплексном использовании. Мировой рынок лития дефицитен, и спрос на этот вид продукции переработки рассолов, по крайней мере, на среднесрочную перспективу обеспечен. На другие виды, вероятнее всего, тоже, если вплотную заняться их маркетингом. Безупречны мотивы содействовать распространению технологии и у третьей группы участников процесса, ибо прибыльное производство - это налогооблагаемая база для любого уровня управления экономикой. Но для того чтобы перечисленные три участника эффективно взаимодействовали, необходим четкий механизм экономических и юридических связей между ними, разработку и контроль которого может и должен обеспечить четвертый участник совместно с правоохранительными органами.

Однако Министерству экономического развития, по всей видимости, не до проблем комплексного использования сырьевых 
ресурсов. По меткому выражению Салтыкова-Щедрина, главная задача власти - постоянно держать народ в изумлении, в данном контексте - выбирать лучший вариант из трех предлагаемых программ стратегического развития страны (Кудрина, Титова, Столыпинского клуба) или согласовывать эти программы между собой.

Конечно, большинство проблем комплексной переработки сырья в рассматриваемом примере самостоятельно могли бы разрешить такие мощные ведомства, как Минатом и Министерство энергетики. К сожалению, попытки разработчиков ноу-хау привлечь их на свою сторону не увенчались успехом. «Это - не наша задача» - вот ответ на приглашение к сотрудничеству. По всей видимости, ведомственный подход к деловым отношениям с партнерами по бизнесу не изжит с советских времен, особенно в закрытых и полузакрытых организациях. Хотя рыночные отношения им не чужды, но только узко в интересах своего ведомства. Оказывается, для них спокойней и проще закачивать рассолы в пласты-коллекторы только лишь после извлечения противогололедного материала ПХКМ, который пока еще производится, чем заниматься «непрофильной» комплексной переработкой с получением остальных попутных продуктов.

Вот так и получается, что общегосударственные интересы пытается обеспечивать в основном лишь научное сообщество в меру своих возможностей, которые как раз всемогущий «четвертый участник» и урезает постоянно.

Проблематика совершенствования методов и материалов для производства литий-ионных аккумуляторов, которые сегодня являются самыми распространенными в мире и используются во многих устройствах - от мобильных телефонов до электромобилей, всегда в поле зрения сибирских ученых. Из последних достижений, привлекших внимание мировой науки, следует отметить разработки ИХТТМ СО РАН по созданию нового катодного материала на основе наноразмерного литий-марганцевого оксида вместо дорогостоящего, с низкой производительностью кобальта лития. Еще 15 лет назад считалось, что в литий-ионных аккумуляторах наноматериалы не будут работать. Помимо того, что новый материал делает батареи более емкими и значительно увеличивает скорость заряда, с помощью механохимии нужное соединение удалось синтезировать при комнатной температуре, без всякого нагрева.

Широкому применению в отечественном производстве достижений науки призван способствовать федеральный закон от 21 июля 2014 г. № 219-ФЗ «О внесении изменений в Федеральный закон “Об охране окружающей среды” и отдельные законодательные акты Российской Федерации». Закон формирует правовые основы и стимулы для модернизации производства, снижения загрязнения окружающей среды, для энергосбережения и ресурсосбережения на основе внедрения наилучших доступных технологий наилучших доступных технологий, критериями отнесения технологических процессов к которым являются: наименьший уровень негативного воздействия на окружающую среду; экономическая эффективность внедрения и эксплуатации; применение ресурсосберегающих и энергосберегающих методов; промышленное внедрение на двух и более объектах в РФ, оказывающих негативное воздействие на окружающую среду [9]. Важными документами для преобразования отечественного производства являются отраслевые справочники наилучших доступных технологий, которые разрабатываются в качестве документов национальной системы стандартизации и которых до 2018 г. будет разработано 47 (из них 12 в 2016 г. и 25 в 2017 г.).

Приведенный выше анализ наглядно доказывает, что комплексная переработка сырья является важнейшим фактором эффективности наилучших доступных технологий. С целью скорейшей замены экологически опасных технологий на безотходные комплексные предлагаем следующее.

$\sqrt{ }$ Ввести в справочниках наилучших доступных технологий понятие категорий технологий по степени использования исходного сырья. Технологиям, с помощью которых перерабатывается почти все сырье, присваивается первая категория, перерабатывающих до 75\% - вторая, от 74 до 50\% - третья, от 49 до 25\% четвертая. К пятой категории относятся все остальные.

$\sqrt{ }$ Использовать материальные и моральные стимулы поощрения объектов и субъектов промышленного производства в привязке к названной классификации категорий наилучших доступных технологий: 
- за разработку и применение технологий только 1-й и 2-й категорий - на вновь создаваемых производствах;

- за стимулирование замены технологий пятой категории на те, которые комплексно используют сырье,- на действующих производствах.

Виды поощрений могут быть самыми разнообразными. Наиболее эффективны, на наш взгляд, дотации из федеральных и региональных бюджетов на период разработки и освоения наилучших доступных технологий и весомое снижение налогов в период последующей эксплуатации технологий. Весьма продуктивными могут оказаться и моральные стимулы.

\section{Литература}

1. Ферсман А. Е. Комплексное использование ископаемого сырья.- Л.: АН СССР, 1932.- $20 \mathrm{c}$.

2. Ларичкин Ф.Д., Пономаренко Т.В. Затраты в комбинированных горно-промышленных производствах: формирование и управление. Учебное пособие.- Апатиты: Изд. Кольского научного центра РАН, 2012.-154 c.

3. Рябцев А.Д., Коцупало Н. П., Титаренко В.И. и др. Комплексная переработка поликомпонентных литиеносных рассолов с предварительным их обогащением по литию / Под ред. Н. П. Коцупало; Закрытое акционерное общество «Экостар-Наутех».- Новосибирск: Академическое изд-во «Гео», 2014.- 172 с.

4. Рябцев А. Д., Ягольницер М.А., Коцупало Н. П. и др. Перспективы комплексной переработки литиеносных поликомпонентных рассолов России // Минеральные ресурсы России. - 2007. - № 6. - С. 44-50.

5. Кин А. А. Магистральный трубопровод «Сила Сибири»: основные положения крупномасштабного проекта // Регион: экономика и социология.- 2016.- № 2.- С. 154-164.

6. Рюмина Е. В. Экономический анализ ущерба от экологических нарушений.- М.: Наука, 2009.- 331 с.

7.Методика определения предотвращенного экологического ущерба./ Госкомитет по охране окружающей среды.- М.: Экономика, 1999.- 71 с. 8. Журавель Н. М. Экологизация финансовых показателей при реализации наилучших доступных технологий // Регион: экономика и социология.- 2011.- № 4.- С. 212-229.

9. Кучкаров 3. А., Максименко Ю. Л., Сокорнова Т.В. Наилучшие доступные технологии: подготовка к внедрению // Экология производства.- 2015.- № 11.- С. 38-45. 